\title{
Differences in maladaptive schemas between patients suffering from chronic and acute posttraumatic stress disorder and healthy controls
}

This article was published in the following Dove Press journal:

Neuropsychiatric Disease and Treatment

10 July 2015

Number of times this article has been viewed

\author{
Alireza Ahmadian ${ }^{1,2}$ \\ Jafar Mirzaee' \\ Maryam Omidbeygi' \\ Edith Holsboer-Trachsler ${ }^{3}$ \\ Serge Brand ${ }^{3,4}$ \\ 'Department of Psychology, Kharazmi \\ University, ${ }^{2}$ Sadr Psychiatric Hospital, \\ Janbazan Medical and Engineering \\ Research Center (JMERC), Tehran, \\ Iran; ${ }^{3}$ Psychiatric Clinics of the \\ University of Basel, Center for \\ Affective, Stress and Sleep Disorders, \\ ${ }^{4}$ Department of Sport, Exercise \\ and Health, Sport Science Section, \\ University of Basel, Basel, Switzerland
}

Background: War, as a stressor event, has a variety of acute and chronic negative consequences, such as posttraumatic stress disorder (PTSD). In this context, early maladaptive schema-based problems in PTSD have recently become an important research area. The aim of this study was to assess early maladaptive schemas in patients with acute and chronic PTSD.

Method: Using available sampling methods and diagnostic criteria, 30 patients with chronic PTSD, 30 patients with acute PTSD, and 30 normal military personnel who were matched in terms of age and wartime experience were selected and assessed with the Young Schema Questionnaire-Long Form, Beck Depression Inventory second version (BDI-II), the Beck Anxiety Inventory (BAI), and the Impact of Events Scale (IES).

Results: Both acute and chronic PTSD patients, when compared with normal military personnel, had higher scores for all early maladaptive schemas. Additionally, veterans suffering from chronic PTSD, as compared with veterans suffering from acute PTSD and veterans without PTSD, reported more impaired schemas related, for instance, to Self-Control, Social Isolation, and Vulnerability to Harm and Illness.

Discussion: The results of the present study have significant preventative, diagnostic, clinical, research, and educational implications with respect to PTSD.

Keywords: veterans, PTSD, depression, anxiety

\section{Introduction}

Traumas may last mere seconds but can have a lifelong impact. In the field of mental health care, the term "trauma" can refer to a wide range of disturbing experiences beyond the daily norm, which produce stress and fear at levels beyond those that could normally be handled. ${ }^{1}$ In effect, traumas are considered as events beyond the scope of everyday experience that can produce pathological symptoms in the victim. They can include exposure to distressing scenes of war and bombardment and witnessing of actual or threatened deaths, or major wounds or injuries, or injuries threatening to cause impairments. Responses to these events and experiences can be evaluated in terms of the diagnostic criteria for posttraumatic stress disorder (PTSD) as set out in the Diagnostic and Statistical Manual of Mental Disorders, Fourth Edition, Text Revision (DSM-IV-TR). ${ }^{2}$ According to these diagnostic criteria, PTSD has three major symptom categories: reexperience of distressing events (at least one symptom), permanent avoidance (three symptoms), and signs of persistent hyperarousal. ${ }^{3}$ Through continuous and uncontrollable thoughts and ruminations, dreams, and nightmares, the victim relives and reexperiences the event; he/she avoids whatever reminds him/her of the trauma; and is hypervigilant toward inner and outer stimuli. Findings from
Correspondence: Jafar Mirzaee Sadr Psychiatric Hospital, Delpazir Alley, Rahmani Street, Piroozi Square, Sadr Highway, I93997443I Tehran, Iran Tel +989123170267

$\mathrm{Fax}+982122545994$

Email Jafarmirzaee48@gmail.com 
epidemiology studies indicate that prevalence rates for PTSD differ between men and women; from 10\%-12\% of women are affected by PTSD, while $5 \%-6 \%$ of men suffer from this condition. Overall, $7 \%-12 \%$ of the population experience PTSD at least once in their lifetime. Additionally, almost $80 \%$ of patients with PTSD have a comorbid psychological disorder. $^{4}$

According to the diagnostic criteria of the DSM-IV-TR, ${ }^{2}$ if symptoms of anxiety appear within 4 weeks of the trauma and have persisted usually for no longer than 3 months, ${ }^{2}$ a diagnosis of acute stress disorder can be made. But if the symptoms persist for more than 3 months, ${ }^{2}$ a diagnosis of chronic PTSD would be considered. ${ }^{3}$ However, we note that in the Diagnostic and Statistical Manual of Mental Disorders, Fifth Edition (DSM-5), ${ }^{5}$ the concepts of acute and chronic PTSD were omitted; on the flip side, the criteria D (negative alterations in cognitions and mood associated with the traumatic event) and E (marked alterations in arousal and reactivity associated with the traumatic event) and the specifications of "with dissociative symptoms" (depersonalization, derealization) were introduced for the first time in DSM-5. Symptoms of the disorder usually appear shortly after the precipitating experience(s). However, in some cases, there can be latency, meaning that after the traumatic experience, days or even months may pass without any noticeable symptom. To address these cases, the DSMIV-TR and DSM-5 5 introduced the expression of "delayed expression of symptoms". Symptoms usually fade away on their own within 6 months of the trauma, but some may last for years. For example, the findings from one study showed that of 2,700,000 combatants involved in the Vietnam war, approximately 500,000-700,000 (ie, 20\%-25\%) were still struggling with PTSD. ${ }^{6}$

The DSM ${ }^{2,5}$ treats war as a source of mentally disturbing experiences that can produce symptoms of PTSD. One of the most complex ways in which PTSD can develop is as a consequence of disturbing battlefield experiences, with the physical and mental symptoms resulting from associated anxiety states being considered the most incapacitating, producing numerous problems for soldiers, their families, and society as a whole. Consistent with this, it is notable that 34 years after the outbreak of the Iraq-Iran war and 26 years on from its conclusion, many veterans are still suffering from psychological disorders comorbid with PTSD. ${ }^{7}$

The appearance and establishment of maladaptive schemas are major consequences of PTSD. Hence, issues concerning early maladaptive schemas in PTSD have become an important field of study in recent years. ${ }^{8-10}$ According to
Ball and Cecero, ${ }^{11}$ after becoming acute, early maladaptive schemas act as personality traits, and the high-level prevalence of early maladaptive schemas in people suffering from PTSD in comparison with other mental disorders has given rise to interest in the application of Young's theory with respect to these patients. ${ }^{8}$

According to Young et al, ${ }^{12}$ schemas that are foundations for further psychological disorders can be described as maladaptive. Early maladaptive schemas are self-defeating emotional and cognitive patterns established in childhood and repeated throughout life. ${ }^{12}$ Following from Young et al, ${ }^{12} 18$ maladaptive schemas have been identified, grouped into five schema domains. The first domain concerns Disconnection/ Rejection and includes five schemas formed as a consequence of unmet needs, such as for security and empathy. These are Abandonment/Instability, Mistrust/Abuse, Emotional Deprivation, Defectiveness/Shame, and Social Isolation/ Alienation. The second domain includes schemas centered on Impaired Autonomy/Performance, ie, schemas formed in the context of families in which children's self-esteem is belittled and their autonomy undermined. These are: Dependence/Incompetence, Vulnerability to Harm and Illness, Enmeshment/Undeveloped Self, and Failure. The third domain includes the schemas of Entitlement/Grandiosity and Insufficient Self-Control/Self-Discipline, which focus on lack of commitment, irresponsibility, and lack of respects for others' rights or appreciation of limits. With an emphasis on extreme attention to others' needs and emotions, the fourth domain is named Other-Directedness and includes three schemas: Subjugation, Self-Sacrifice, and ApprovalSeeking/Recognition-Seeking. The fifth and last domain is Hypervigilance/Inhibition. It includes four schemas: Negativity/Pessimism, Emotional Inhibition, Unrelenting Standards/Hypercriticalness, and Punitiveness. ${ }^{13}$

Studies have shown that early maladaptive schemas play pivotal roles in addiction, ${ }^{14}$ marital infidelity, ${ }^{15}$ obsessive/compulsive disorder, ${ }^{16}$ personality disorders, depression, and anxiety. ${ }^{17,18}$ Cockram et $\mathrm{al}^{8}$ highlighted the role of early maladaptive schemas in PTSD among Australian and New Zealander veterans, while Boudoukha et $\mathrm{al}^{9}$ identified a similar role in French prison officers suffering from PTSD. The results of the Cockram et $\mathrm{al}^{8}$ study indicated that the early maladaptive schemas of Emotional Inhibition, Self-Sacrifice, Entitlement/Grandiosity, Insufficient Self-Control, Failure, Mistrust/Abuse, Social Isolation/Alienation, Defectiveness/ Shame, and Emotional Deprivation were significant characteristics of patients suffering from PTSD. Boudoukha et $\mathrm{al}^{9}$ found that early maladaptive schemas of Mistrust/Abuse, 
Dependence/Incompetence, Insufficient Self-Control, Unrelenting Standards, Vulnerability to Harm and Illness, Emotional Inhibition, and Emotional Deprivation were, in this order, displayed with higher intensity in the prison officer sample.

Overall, the cognitive symptoms of PTSD are usually determined by a variety of negative experiences and emotions, such as grief, anger, guilt, and feelings of inability to control negative emotions. By considering the psychological damage caused by past events and their traces in autobiographical memory and by studying the mechanisms, foundations, and treatment process of damaged emotional schema of PTSD patients, the prospects of recovery may be improved, and the effectiveness of treatment of these patients may be enhanced. ${ }^{3}$ Accordingly, the aims of the present study were to assess and describe maladaptive schemas of Iranian veterans suffering from PTSD, to better understand the etiology and prognosis in the case of this disorder, and the need for effective clinical intervention. The current study attempted therefore to investigate the presence of early maladaptive schemas in patients suffering from acute PTSD, patients suffering from chronic PTSD, and healthy military personnel who experienced war traumas, though without developing a PTSD.

\section{Method}

This was an exploratory study taking a retrospective and comparative approach. The participants were selected from among war veterans at the Sadr Psychiatric Center (Tehran, Iran). The sample included 30 patients suffering from chronic PTSD (war trauma), 30 patients with acute PTSD, and 30 armed forces personnel of similar age and experience of war who had also confronted traumatic events comparable with those experienced by the other groups but without displaying either chronic or acute PTSD symptoms. Inclusion criteria for patients were as follows: 1) presence of acute or chronic PTSD symptoms, as diagnosed by an experienced psychiatrist not further involved in the study; 2) aged 25-45 years; 3) having some education; 4) willing and able to participate at the study; and 5) written informed consent. Exclusion criteria were: 1) a medical history of physical illnesses interfering with PTSD symptoms; 2) receiving treatment for mental illness 6 months prior to research; and 3) drug abuse. To achieve the aforementioned goals, in addition to a psychiatric diagnosis, the Structured Clinical Interview for the DSM-IV (SCID) ${ }^{19}$ was conducted by a clinical psychologist not otherwise involved in the study. The Tehran University of Medical Sciences ethics committee (Tehran, Iran) approved the study, and the entire study was conducted following the rules laid down in the Declaration of Helsinki.

Demographic and psychological characteristics of the participants are presented in Table 1 .

The results of a one-way analysis of variance (ANOVA) indicated that age $(F(2,87)=0.03 ; P>0.10)$ and level of education $(F(2,87)=1.09 ; P>0.10)$ did not differ significantly across the three groups.

\section{Research tools \\ SCID - clinician version}

The version of the SCID $^{19}$ used in the study was the Farsi/ Persian (expert-rated) version, developed by Sharifi et al. ${ }^{20}$ This tool was adopted for diagnosis of Diagnostic and Statistical Manual of Mental Disorders, Third Edition, Revised (DSM-III-R) disorders. This interview has unique features not present in previous versions. The tool is simple to use and includes a review section in which the patient can define the current illness. The SCID also contains a design pattern that allows the researcher to discard diagnosis levels irrelevant to the patient. The SCID has six patterns for identifying Axis I and Axis II disorders. Although the patterns are considered in alphabetical order, a clinical specialist can change this order or exclude one of the patterns. These patterns are: A (behavior), B (psychotic symptoms), C (psychotic disorders), D (behavioral disorders), E (drug-related disorders), and F (stress disorders). Additionally, the SCID includes diagnosis patterns for Axis II disorder. The SCID can be applied to patients in psychotherapy and medical patients. The most appropriate age for its implementation is 18 years and above.

Table I Descriptive overview of demographic data and psychopathology, separately by group (patients with chronic and acute PTSD, and healthy controls)

\begin{tabular}{|c|c|c|c|c|c|c|}
\hline \multirow[t]{2}{*}{ Group } & \multirow[t]{2}{*}{ Frequency } & \multicolumn{5}{|l|}{ Mean (SD) } \\
\hline & & Age & Level of education & Duration of disorder (years) & Anxiety & Depression \\
\hline PTSD-C & 30 & $44.63(3.21)$ & $13.43(1.73)$ & $14.67(2.76)$ & $38.37(4.29)$ & $42.97(4.63)$ \\
\hline PTSD-A & 30 & $42.97(5.30)$ & $13.53(1.74)$ & N/A & $50.60(5.17)$ & $47.30(4.75)$ \\
\hline $\mathrm{HC}$ & 30 & $43.27(5.16)$ & 13.47 (1.63) & N/A & I $5.63(2.4 \mid)$ & $20.47(3.73)$ \\
\hline
\end{tabular}

Abbreviations: HC, healthy controls; PTSD-A, acute posttraumatic stress disorder; PTSD-C, chronic posttraumatic stress disorder; SD, standard deviation; N/A, not applicable. 
Beck Depression Inventory second version (BDI-II) The BDI-II (self-rated) ${ }^{21}$ is an inventory consisting of a set of 21 statements, with four response choices for each. Respondents choose the alternative closest to their present condition. Each response is assigned a score of 0-3. Overall scores may thus vary from 0 to 63 , with higher scores reflecting more severe depression (Cronbach's alpha coefficient $=0.92$ ).

\section{Beck Anxiety Inventory (BAI)}

The BAI (self-rated) ${ }^{22}$ is a questionnaire consisting of 21 statements, each describing a common symptom of anxiety (mental, physical, and stress symptoms). The respondent chooses from among four alternative responses to each statement to describe the severity of his/her anxiety. The alternatives are scored $0-3$. Hence total scores for this test can range from 0 to 63 , with higher scores reflecting increased symptoms of anxiety (Cronbach's alpha coefficient $=0.94$ ).

\section{Young Schema Questionnaire - Long Form}

The Young Schema Questionnaire - Long Form ${ }^{23,24}$ consists of 232 items and assesses 18 different schemas, as proposed by Young et al. ${ }^{22} \mathrm{~A}$ previous study has confirmed its effectiveness in distinguishing patients on the basis of maladaptive schemas. ${ }^{23}$ Cronbach's alphas for the different schemas in the present study were as follows: Dependence/Incompetence (0.95); Vulnerability to Harm and Illness (0.94); Enmeshment/Undeveloped Self (0.97); Failure (0.95); Entitlement/Grandiosity (0.92); Insufficient Self-Control/Self-Discipline (0.97); Abandonment/Instability (0.94); Mistrust/Abuse (0.97); Emotional Dependency (0.96); Defectiveness/Shame (0.96); Social Isolation/Alienation (0.94); Subjugation (0.96); Self-Sacrifice (0.86); Approval-Seeking/Recognition-Seeking (0.95); Negativity/Pessimism (0.97); Emotional Deprivation (0.96); Unrelenting Standards/Hypercriticalness (0.96); and Punishment (0.96). For the total score, alpha was 0.96.

\section{The Impact of Event Scale - Revised (IES-R)}

The IES-R (self-assessment) tool ${ }^{25}$ is consistent with DSM-IV criteria for identifying PTSD. Whereas the IES covers only two out of the four DSM-IV criteria for identifying PTSD, namely unwanted thoughts and avoidance, the IES-R was designed to include symptoms of hyperarousal, the fourth criterion for PTSD. This test includes 22 items. Six of these new items concern symptoms of hyperarousal, such as anger and irritability, severe response to unexpected stimuli, difficulty in concentration, being alert, and a new item, unwanted thoughts involving recurring memories of traumatic events. Respondents consider each item on the basis of their experiences over the previous 7 days, giving a rating for the item on a scale of 0 (never), 1 (occasionally), 2 (sometimes), 3 (usually), or 4 (severely) (Cronbach's alpha coefficient $=0.91$ ).

\section{Statistical analysis}

A series of ANOVAs were performed with the factor group (PTSD-chronic, PTSD-acute, and healthy controls) and the dependent variables of symptoms of anxiety and depression, and the dimensions of schemas. Further, post hoc tests after Bonferroni-Holm correction for $P$-values were performed. Indeed, to avoid the risk to observing significant $P$-values because of repeated post hoc analyses, we introduced the Bonferroni-Holm correction for $P$-values, leading to more conservative $P$-value estimations. Statistics was performed with SPSS $^{\circledR} 20.0$ (IBM Corp., Armonk NY, USA) for Windows ${ }^{\circledR}$.

\section{Results}

\section{Symptoms of anxiety and depression}

There were significant differences between the groups with respect to anxiety $(F(2,87)=556.33 ; P<0.001)$ and depression $(F(2,87)=322.24 ; P<0.001)$. Post hoc tests after Bonferroni-Holm correction for $P$-values revealed that compared with patients with acute PTSD and healthy controls, patients with chronic PTSD reported highest scores for the symptoms of anxiety and depression.

\section{Dimensions of schemas, separately by group}

Table 2 reports the descriptive and inferential statistics for group comparisons as the independent variable, and schemas as dependent variables.

The analyses confirmed that there were significant group effects for all maladaptive schemas. The Bonferroni post hoc tests showed that for the primary maladaptive schemas of Dependence/Incompetence, Vulnerability to Harm and Illness, Enmeshment/Undeveloped Self, Abandonment/ Instability, Mistrust/Abuse, Social Isolation/Alienation, Subjugation, Self-Sacrifice, Unrelenting Standards/Hypercriticalness, Entitlement/Grandiosity, Insufficient Self-Control/ Self-Discipline, Defectiveness/Shame, and Punishment, both the acute and chronic PTSD patients had higher scores than did the healthy controls and that the chronic PTSD patient group had higher scores than did the acute patients. With respect to the Failure, Emotional Dependency, ApprovalSeeking/Recognition-Seeking, Negativity/Pessimism, and Emotional Deprivation schemas, there were no significant 
Table 2 Results from one-way variance and Bonferroni post hoc test for comparison of primary maladaptive schemas

\begin{tabular}{|c|c|c|c|c|c|}
\hline $\begin{array}{l}\text { Early maladaptive } \\
\text { schemas }\end{array}$ & Group & Mean (SD) & $\begin{array}{l}F \\
d f=2.63\end{array}$ & $\eta^{2}$ & $\begin{array}{l}\text { Bonferroni post hoc } \\
\text { test results }\end{array}$ \\
\hline Dependence/ & PTSD-C & $62.27(4.77)$ & $385.54 * * *$ & 0.89 & PTSD-C > PTSD-A \\
\hline \multirow[t]{2}{*}{ Incompetence } & PTSD-A & $49.77(5.59)$ & & & PTSD-C $>\mathrm{HC}$ \\
\hline & $\mathrm{HC}$ & $27.17(4.66)$ & & & PTSD-A > HC \\
\hline Vulnerability to Harm & PTSD-C & $49.37(7.10)$ & $319.65 * * *$ & 0.87 & PTSD-C > PTSD-A \\
\hline \multirow[t]{2}{*}{ and IIIness } & PTSD-A & $52.83(4.59)$ & & & PTSD-C $>\mathrm{HC}$ \\
\hline & $\mathrm{HC}$ & $19.53(4.79)$ & & & PTSD-A > HC \\
\hline Enmeshment/ & PTSD-C & $47.47(3.85)$ & $531.83 * * *$ & 0.92 & PTSD-C > PTSD-A \\
\hline \multirow[t]{2}{*}{ Undeveloped Self } & PTSD-A & $42.70(4.66)$ & & & PTSD-C $>\mathrm{HC}$ \\
\hline & $\mathrm{HC}$ & $15.97(3.50)$ & & & PTSD-A > HC \\
\hline \multirow[t]{3}{*}{ Failure } & PTSD-C & $38.43(3.34)$ & $278.67 * * *$ & 0.86 & PTSD-C $>\mathrm{HC}$ \\
\hline & PTSD-A & $37.17(3.08)$ & & & PTSD-A > HC \\
\hline & $\mathrm{HC}$ & $16.20(5.45)$ & & & \\
\hline \multirow[t]{3}{*}{ Entitlement/Grandiosity } & PTSD-C & $29.60(4.5 I)$ & $94.91 * * *$ & 0.68 & PTSD-C $<$ PTSD-A \\
\hline & PTSD-A & $34.00(5.74)$ & & & PTSD-C $>\mathrm{HC}$ \\
\hline & $\mathrm{HC}$ & $17.70(3.76)$ & & & PTSD-A > HC \\
\hline Insufficient Self-Control/ & PTSD-C & $52.63(6.25)$ & $311.67 * * *$ & 0.87 & PTSD-C $<$ PTSD-A \\
\hline \multirow[t]{2}{*}{ Self-Discipline } & PTSD-A & $58.90(7.03)$ & & & PTSD-C $>\mathrm{HC}$ \\
\hline & $\mathrm{HC}$ & $22.63(4.47)$ & & & PTSD-A > HC \\
\hline \multirow[t]{3}{*}{ Abandonment/Instability } & PTSD-C & $55.93(9.99)$ & $75.82 * * *$ & 0.64 & PTSD-C > PTSD-A \\
\hline & PTSD-A & $50.87(8.36)$ & & & PTSD-C $>\mathrm{HC}$ \\
\hline & $\mathrm{HC}$ & $29.53(7.85)$ & & & PTSD-A > HC \\
\hline \multirow[t]{3}{*}{ Mistrust/Abuse } & PTSD-C & $69.97(4.79)$ & $469.58 * * *$ & 0.91 & PTSD-C > PTSD-A \\
\hline & PTSD-A & $65.53(7.82)$ & & & PTSD-C $>\mathrm{HC}$ \\
\hline & $\mathrm{HC}$ & $26.72(4.63)$ & & & PTSD-A > HC \\
\hline \multirow[t]{3}{*}{ Emotional Dependency } & PTSD-C & $41.30(3.28)$ & $500.00 * * *$ & 0.92 & PTSD-C > HC \\
\hline & PTSD-A & $40.10(4.44)$ & & & PTSD-A > HC \\
\hline & $\mathrm{HC}$ & $14.43(3.31)$ & & & \\
\hline \multirow[t]{3}{*}{ Defectiveness/Shame } & PTSD-C & $47.50(5.35)$ & $255.50 * * *$ & 0.87 & PTSD-C $<$ PTSD-A \\
\hline & PTSD-A & $62.23(6.31)$ & & & PTSD-C $>\mathrm{HC}$ \\
\hline & $\mathrm{HC}$ & $26.17(6.88)$ & & & PTSD-A > HC \\
\hline Social Isolation/ & PTSD-C & $41.47(3.99)$ & $237.92 * * *$ & 0.84 & PTSD-C > PTSD-A \\
\hline \multirow[t]{2}{*}{ Alienation } & PTSD-A & $36.90(5.26)$ & & & PTSD-C $>\mathrm{HC}$ \\
\hline & $\mathrm{HC}$ & $18.17(3.75)$ & & & PTSD-A $>\mathrm{HC}$ \\
\hline \multirow[t]{3}{*}{ Subjugation } & PTSD-C & $42.43(2.54)$ & $628.57 * * *$ & 0.94 & PTSD-C > PTSD-A \\
\hline & PTSD-A & $41.93(3.93)$ & & & PTSD-C $>\mathrm{HC}$ \\
\hline & $\mathrm{HC}$ & $16.30(3.16)$ & & & PTSD-A > HC \\
\hline \multirow[t]{3}{*}{ Self-Sacrifice } & PTSD-C & $62.40(9.92)$ & $55.69 * * *$ & 0.54 & PTSD-C > PTSD-A \\
\hline & PTSD-A & $53.20(9.99)$ & & & PTSD-C $>\mathrm{HC}$ \\
\hline & $\mathrm{HC}$ & 34.30 (II.47) & & & PTSD-A > HC \\
\hline Approval-Seeking/ & PTSD-C & $53.77(7.11)$ & $215.41 * * *$ & 0.83 & PTSD-C $>$ HC \\
\hline \multirow[t]{2}{*}{ Recognition-Seeking } & PTSD-A & $52.43(6.58)$ & & & PTSD-A > HC \\
\hline & $\mathrm{HC}$ & $24.03(4.89)$ & & & \\
\hline \multirow[t]{3}{*}{ Negativity/Pessimism } & PTSD-C & $47.97(3.72)$ & $407.01 * * *$ & 0.90 & PTSD-C $>\mathrm{HC}$ \\
\hline & PTSD-A & $47.58(3.83)$ & & & PTSD-A > HC \\
\hline & $\mathrm{HC}$ & $19.93(5.35)$ & & & \\
\hline \multirow[t]{3}{*}{ Emotional Inhibition } & PTSD-C & $38.53(2.31)$ & $375.06 * * *$ & 0.90 & PTSD-C $>\mathrm{HC}$ \\
\hline & PTSD-A & $39.13(4.47)$ & & & PTSD-A > HC \\
\hline & $\mathrm{HC}$ & $15.59(4.13)$ & & & \\
\hline Unrelenting Standards/ & PTSD-C & $66.87(4.29)$ & $316.28 * * *$ & 0.88 & PTSD-C > PTSD-A \\
\hline \multirow[t]{2}{*}{ Hypercriticalness } & PTSD-A & $62.10(7.5 \mathrm{I})$ & & & PTSD-C $>\mathrm{HC}$ \\
\hline & $\mathrm{HC}$ & $30.33(6.12)$ & & & PTSD-A > HC \\
\hline \multirow[t]{3}{*}{ Punishment } & PTSD-C & $56.83(3.36)$ & $510.90 * * *$ & 0.92 & PTSD-C $<$ PTSD-A \\
\hline & PTSD-A & $61.10(4.17)$ & & & PTSD-C $>\mathrm{HC}$ \\
\hline & $\mathrm{HC}$ & $27.67(5.44)$ & & & PTSD-A > HC \\
\hline
\end{tabular}

Note: $* * * P \leq 0.001$.

Abbreviations: HC, healthy controls; PTSD-A, acute posttraumatic stress disorder; PTSD-C, chronic posttraumatic stress disorder; SD, standard deviation. 
differences between the two patient groups, though both groups had significantly higher scores than did the control group.

\section{Discussion and conclusion}

The key findings of the present study were that among veterans suffering from both acute and chronic PTSD, compared with healthy controls, distinct dysfunctional schemas were observable and that veterans suffering from chronic PTSD reported more dysfunctional schemas as compared with veterans suffering from acute PTSD. Importantly, data of veterans suffering from PTSD were compared with those of veterans who were also exposed to war trauma, though without developing PTSD.

PTSD is among the most debilitating and complex of mental disorders. This disorder develops as the result of experiencing or witnessing traumatic events, having complex effects on the individual. It is worth noting that there is not a great deal of research into PTSD and primary maladaptive schemas, and, indeed, no comparisons have been made between acute and chronic PTSD patients with respect to these schemas. Thus, interpretation of this data presents challenges. The present research revealed differences between each of the three groups studied, with both acute and chronic PTSD patients scoring higher on maladaptive schemas than the control group of military personnel who experienced similar war trauma, though without developing PTSD.

The primary maladaptive schemas of Failure, Emotional Dependency, Approval-Seeking/Recognition-Seeking, Negativity/Pessimism, and Emotional Deprivation did not significantly differ between the two PTSD groups. The acute patients scored higher than did the chronic patients on the primary maladaptive schemas of Entitlement/Grandiosity, Insufficient Self-Control/Self-Discipline, Defectiveness/ Shame and Punishment. The signs of this psychological damage are evident in a lack of behavioral control, aggression, crying, mental/physical instability, together with feelings of suffering retribution (being punished), and while not deserving this tremendous pressure and torment, ${ }^{12,13}$ all signs were manifested in acute PTSD. Thus, the difference in severity of the primary maladaptive schemas between acute PTSD and chronic PTSD patients makes sense. However, we note that the present data do not allow a deeper introspection as to what extent the present maladaptive schemas developed and emerged during former and earlier stages of life. Consequently, it remains unclear to what extent the present differences of schemas reflect former maladaptive schemas triggered and increased by the traumatic events. Nevertheless, given that in the present study, these differences in cognitiveemotional processes, ie, in schemas, could be detected, these observations open an excellent avenue in differentiating psychotherapeutic interventions among veterans suffering PTSD. More specifically, as the present data suggest, veterans suffering from chronic PTSD, compared with veterans without PTSD and veterans suffering from acute PTSD, reported more impaired cognitive-emotional processes, ie, schemas, as regards, for instance, Shame, Insufficient Self-Control, and Social Isolation. Accordingly, psychotherapeutic interventions might specifically focus on these schemas.

Given these results, we conclude that primary maladaptive schemas arise out of the interaction of internal states with the individual's surroundings and, more specifically, that early experiences have a major role in the creation of primary maladaptive schemas. ${ }^{12,13}$ Ledoux et $\mathrm{al}^{26}$ argued that these schemas may be produced by harmful events, such as abandonment and abuse. In a biological analysis, Ledoux et $\mathrm{al}^{26}$ proposed that when a harmful event occurs, conscious memory is protected by a system related to the hippocampus and cortical areas of the brain, while unconscious memories are formed by fear-conditioning mechanisms, which work through the amygdala. These two systems are both active and store different information about traumatic events. Each of these systems can evaluate memories every time the patient encounters stimuli present in the trauma. The effects of the amygdala evaluation take the form of physical awareness to repel dangers, while the hippocampus system will recall memories consciously. The amygdala stores emotional memories, but the hippocampus and brain cortical areas maintain cognitive memories. Emotional responses can be triggered without the activation of brain cortical process systems involved in thinking, logic, and consciousness. ${ }^{26}$ Moreover, given the high degree of overlap between malfunctioning emotional discipline and emotional schemas, it is likely that maladaptive emotional schemas will lead to the emotional disorders ${ }^{27}$ also observed in PTSD.

In the end, given that one persistent feature of anxiety disorders (and particularly PTSD) is avoidance of stressful or trauma-evoking circumstances (as per definitions of PTSD according to the DSM-IV-TR and DSM-5), ${ }^{2,5}$ by working on these schemas, negative and malfunctioning cycles of persistence in acute disorders can be controlled. Moreover, given that PTSD is usually followed by a wide variety of negative emotions, such as grief, wrath, guilt, and shame, it is evident that treatments focusing on different types of maladaptive schemas, and designing therapeutic frameworks with previous maladaptive schemas, can improve cognitive performance and maintain treatment effects. ${ }^{13,26-30}$ Hence, the results of this 
research have many practical implications in the diagnosis, treatment, and symptom maintenance of PTSD.

Finally, it should be mentioned that in common with other studies, the present study suffers from various limitations. First, the cross-sectional design precludes any conclusions as regards causal associations between cognitive-emotional processes (schemas) and the elaboration and perception of PTSD. Second, the lack of longitudinal data is particularly evident in that the influence of early life events remained undisclosed. Third, no analysis of female patients suffering from PTSD and no comparison of PTSD patients with other diagnostic groups were performed. Fourth, moreover, sleep and medication was not assessed, ${ }^{31}$ and no intervention was included. ${ }^{32}$ Fifth, one might object that the diagnosis was based on the DSM-IV-TR2 and not on the DSM-55, which introduced the criterion D (negative alterations in cognitions and mood). However, we think that these negative alterations in cognitions and mood might be best viewed as schemas as proposed by Young et al. ${ }^{12}$ In our opinion, the multitude and variety of maladaptive schemas observed in veterans suffering from chronic (and acute) PTSD do mirror the criterion D introduced in the DSM-5, and, even more importantly, focusing on schemas seems to enhance the utility of the present publication and schema therapy for clinicians. Last, the present pattern of results might have emerged due to further latent but unassessed variables, such as previous pharmacologic and psychotherapeutic treatments. Future studies could profitably focus on relations between primary maladaptive schemas and different aspects of personality, and on other clinical, emotional, and cognitive symptoms of PTSD patients.

\section{Acknowledgments}

We thank Nick Emler (University of Surrey, Surrey, UK) for proofreading the manuscript. Furthermore, we thank Professor Mohammadreza Soroush from the Janbazan Medical and Engineering Research Center (JMERC), Tehran, Iran, for his helpful advice.

\section{Disclosure}

The authors report no conflicts of interest in this work. The entire study was conducted without external funding.

\section{References}

1. Wang L, Zhang J, Shi Z, Zhou M, Huang D, Liu P. Confirmatory factor analysis of posttraumatic stress symptoms assessed by the Impact of Event Scale-Revised in Chinese earthquake victims: examining factor structure and its stability across sex. J Anxiety Disord. 2011;25(3): 369-375.

2. American Psychiatric Association. Diagnostic and Statistical Manual of Mental Disorders. Fourth Edition, Text Revision. Washington, DC: American Psychiatric Association; 2000.
3. Hinton DE, Rivera EI, Hofmann SG, Barlow DH, Otto MW. Adapting CBT for traumatized refugees and ethnic minority patients: examples from culturally adapted CBT (CA-CBT). Transcult Psychiatry. 2012; 49(2):340-365.

4. Sadock BJ, Sadock VA, Ruiz P. Kaplan and Sadock's Comprehensive Textbook of Psychiatry. 9th ed. Philadelphia, PA: Lippincott Williams \& Wilkins; 2009

5. American Psychiatric Association. Diagnostic and Statistical Manual of Mental Disorders. Fifth Edition. Washington, DC: American Psychiatric Association; 2013.

6. Gates MA, Holowka DW, Vasterling JJ, Keane TM, Marx BP, Rosen RC. Posttraumatic stress disorder in veterans and military personnel: epidemiology, screening, and case recognition. Psychol Serv. 2012;9(4):361-382.

7. Ahmadian AR, Nazari AM, Hasanabadi H, Mirzaee J. [Effectiveness of schema therapy based on metaphor on veterans with PTSD]. J Military. 2012;11:21-40. Persian/Farsi.

8. Cockram DM, Drummond PD, Lee CW. Role and treatment of early maladaptive schemas in Vietnam Veterans with PTSD. Clin Psychol Psychother. 2010;17(3):165-182.

9. Boudoukha AH, Przygodzki-Lionet N, Hautekeete M. Traumatic events and early maladaptive schemas (EMS): Prison guard psychological vulnerability. Eur Rev Appl Psychol. In press 2015.

10. Shorey RC, Stuart GL, Anderson S. Differences in early maladaptive schemas in a sample of alcohol and opioid-dependent women: Do schemas vary across disorders? Addict Res Theory. 2013;21(2): 132-140.

11. Ball SA, Cecero JJ. Addicted patients with personality disorders: traits, schemas, and presenting problems. J Pers Disord. 2001;15(1):72-83.

12. Young JE, Klosko JS, Weishaar ME. Schema Therapy: A Practitioner's Guide. New York, NY: Guilford Press; 2003.

13. Arntz A, Gitta J. Schema Therapy in Practice: An Introductory Guide to the Schema Mode Approach. Chichester: John Wiley \& Sons; 2013.

14. Khoshlahjeh A, Abolmaali Alhosseyni KH, et al. Comparison of early maladaptive schemas in thorough over addicted, break down addicted and non-clinical person. Trends in Psychology. 2012;7(23):46-60.

15. Rafiee S, Hatami A, Foroughi A. Relationship between early maladaptive schemas and attachment style in woman with infidelity. Sociology of Women (Journal of Woman and Society). 2011;2(5):21-36.

16. Esmaeeli A, Sohrabi F, Borjali A, Farrokhi N. Active early maladaptive on OCD patients. J Clin Psychol. 2011;1(2):25-43.

17. Platts H, Mason O, Tyson M. Early maladaptive schemas and adult attachment in a UK clinical population. Psychol Psychother. 2005;78 (Pt 4):549-564.

18. Platts H, Tyson M, Mason O. Adult attachment style and core beliefs: are they linked? Clin Psychol Psychother. 2002;9(5):332-348.

19. Spitzer RL, Williams JB, Gibbon M, First MB. The Structured Clinical Interview for DSM-III-R (SCID). I: History, rationale, and description. Arch Gen Psychiatry. 1992;49(8):624-629.

20. Sharifi V, Asadi M, Mohammadi MR, et al. Reliability and validity of structured interview for SCID based on DSM-IV. Trends Cogn Sci. 2004;8:10-22.

21. Beck AT, Ward CH, Mendelson M, Mock J, Erbaugh J. An inventory for measuring depression. Arch Gen Psychiatry. 1961;4:561-571.

22. Beck AT, Epstein N, Brown G, Steer RA. An inventory for measuring clinical anxiety: psychometric properties. J Consult Clin Psychol. 1988; 56(6):893-897.

23. Young JE, Weinberger AD, Beck AT. Cognitive therapy for depression. In: Barlow DH, editor. Clinical Handbook of Psychological Disorders. 3rd ed. New York, NY: Guilford Press; 2001:802-820.

24. Saariaho T, Saariaho A, Karila I, Joukamaa M. The psychometric properties of the Finnish Young Schema Questionnaire in chronic pain patients and a non-clinical sample. J Behav Ther Exp Psychiatry. 2009; 40(1):158-168.

25. Weiss DS, Marmar CR. The Impact of Event Scale-Revised. In JP Wilson, TM Keane, editors. Assessing Psychological Trauma and PTSD: A Practitioner's Handbook. New York: Guilford Press; 1997: 399-411. 
26. Ledoux T, Winterowd C, Richardson T, Clark JD. Relationship of negative self-schemas and attachment styles with appearance schemas. Body Image. 2010;7(3):213-217.

27. Leahy RL. Emotional schema therapy: A bridge over troubled waters. In: Herbert JD, Forman EM, editors. Acceptance and Mindfulness in Cognitive Behavior Therapy: Understanding and Applying the New Therapies. New York, NY: Guilford Press; 2011:105-108.

28. Arntz A, Tiesema M, Kindt M. Treatment of PTSD: a comparison of imaginal exposure with and without imagery rescripting. J Behav Ther Exp Psychiatry. 2007;38(4):345-370.

29. Hackmann A. Imagery rescripting in posttraumatic stress disorder. Cogn Behav Pract. 2011;18(4):424-432.
30. Long ME, Hammons ME, Davis JL, et al. Imagery rescripting and exposure group treatment of posttraumatic nightmares in Veterans with PTSD. J Anxiety Disord. 2011;25(4):531-535.

31. Ahmadpanah M, Sabzeiee P, Hosseini SM, et al. Comparing the effect of prazosin and hydroxyzine on sleep quality in patients suffering from posttraumatic stress disorder. Neuropsychobiology. 2014;69(4): $235-242$.

32. Akbarian F, Bajoghli H, Haghighi M, Kalak N, Holsboer-Trachsler E, Brand $\mathrm{S}$. The effectiveness of cognitive behavioral therapy with respect to psychological symptoms and recovering autobiographical memory in patients suffering from post-traumatic stress disorder. Neuropsychiatr Dis Treat. 2015;11:395-404.

\section{Publish your work in this journal}

Neuropsychiatric Disease and Treatment is an international, peerreviewed journal of clinical therapeutics and pharmacology focusing on concise rapid reporting of clinical or pre-clinical studies on a range of neuropsychiatric and neurological disorders. This journal is indexed on PubMed Central, the 'PsycINFO' database and CAS, and is the official journal of The International Neuropsychiatric Association (INA). The manuscript management system is completely online and includes a very quick and fair peer-review system, which is all easy to use. Visit http://www.dovepress.com/testimonials.php to read real quotes from published authors. 